\title{
Neurological manifestations associated with internal carotid loops and kinks in children
}

\author{
N. B. S. SARKARI, J. MACDONALD HOLMES, AND EDWIN R. BICKERSTAF \\ From the Midland Centre for Neurosurgery and Neurology, Holly Lane, Smethwick
}

Tortuosity, kinking, and looping of the internal carotid artery has been well recognized for many years. Anatomists have described this artery as being remarkable for the number of curvatures in different parts of its course, Coulson (1852) was probably the first to mention looping of the internal carotid artery presenting as a pulsatile swelling in the neck. Otolaryngologists have for long been concerned because of the hazards of fatal haemorrhage after tonsillectomy or removal of the adenoids (Connolly, 1914; Fisher, 1915; Jackson, 1933).

The first mention of tortuosity being related to cerebral ischaemic symptoms seems to have been made by Riser, Géraud, Ducoudray, and Ribaut (1951). McDowell, Schick, Frederick, and Dunbar (1959) reported 20 cases of tortuosity and irregularities of carotid arteries from a study of 68 patients with cerebrovascular disease where no evidence of occlusion could be demonstrated on angiography. All these cases were adults and over 30 years of age. Metz, Murray-Leslie, Bannister, Bull, and Marshall (1961) carried out a retrospective study of 1,000 angiograms and found 161 cases with kinks and loops of the internal carotid artery. There were only four cases under 10 years of age, but the patients who had cerebral symptoms presumably related to these abnormalities were over 40.

In 1965, Weibel and Fields reviewed 2,453 angiograms carried out on 1,407 patients varying in age from 6 weeks to 81 years. In the group with cerebrovascular insufficiency the ages of the patients ranged from 35 to 75 years, $80 \%$ being over 50 . There were five cases below 10 years with tortuosity and kinking but they had no features suggestive of cerebrovascular disease (Weibel and Fields, 1965a, b).

In a Russian paper Garaseferian (1965) described 12 cases who had cerebrovascular insufficiency which seemed mainly related to the internal carotid loops and the youngest patient was 26 years of age. It appears, therefore, that as yet there is no record in the literature where cerebrovascular insufficiency in children could be suggested to be related to internal carotid artery loops. Hence nine cases, eight under 10 years and one 16 years of age, are being reported who presented with symptoms which, in a chils could be attributed to transient ischaemia. Arterios grams were carried out which demonstrated uni lateral or bilateral loops of the cervical portion of the internal carotid arteries. The details submittea below suggest that there may be a definite correlatio $\vec{\Phi}$ between the looping and the clinical syndrome.

\section{CASE 1}

A male child aged 5 was born prematurely with a birth weight of $3 \mathrm{lb} .15 \mathrm{oz}$. $(1.8 \mathrm{~kg})$. After birth developmeres was normal until the age of 12 months when his parents noticed that he was not using his left hand properly $\vec{\Phi} A \vec{b}$ the age of 18 months he was found to have a mildfeft hemiparesis. One month before admission he awoke a 5 a.m. crying and had paralysis of the right side wisch improved completely in the ensuing one hour. Akgl three weeks later he had another attack of transifin weakness of the right side in the early hours of the morning.

On examination he appeared alert and intelligent. There was mild left hemiparesis with spasticity. The left upperp and lower limbs were shorter by $2.5 \mathrm{~cm}$ as compared wit those on the right. The tendon reflexes were exaggerate on both sides and the left plantar reflex extensor. Af other systems were normal.

INVESTIGATIONS Full blood count, ESR, serology, and CSF were essentially normal. Electroencephalograph showed bilateral slow waves, more marked on the right side than the left with spikes over the right tempora region. The radiographs of chest and skull were normai: Bilateral carotid arteriograms showed internal carotio loops on both sides, more marked on the right (Fig. than that on the left (Fig. 2). The one on the right was $2.2 \mathrm{~cm}$ above the bifurcation and that on the left was $2 \mathrm{~cm}$. The anterior cerebral arteries were shifted to the right side, suggesting right cerebral atrophy.

Follow-UP $\mathrm{He}$ is now $8 \frac{1}{2}$ years old and is in a specia school and is mentally backward. He has grand ma attacks once every six months or so. The left arm and let lower limb are thinner and shorter than the right and arespastic.

CASE 2

A female child aged 10 years was admitted with the 


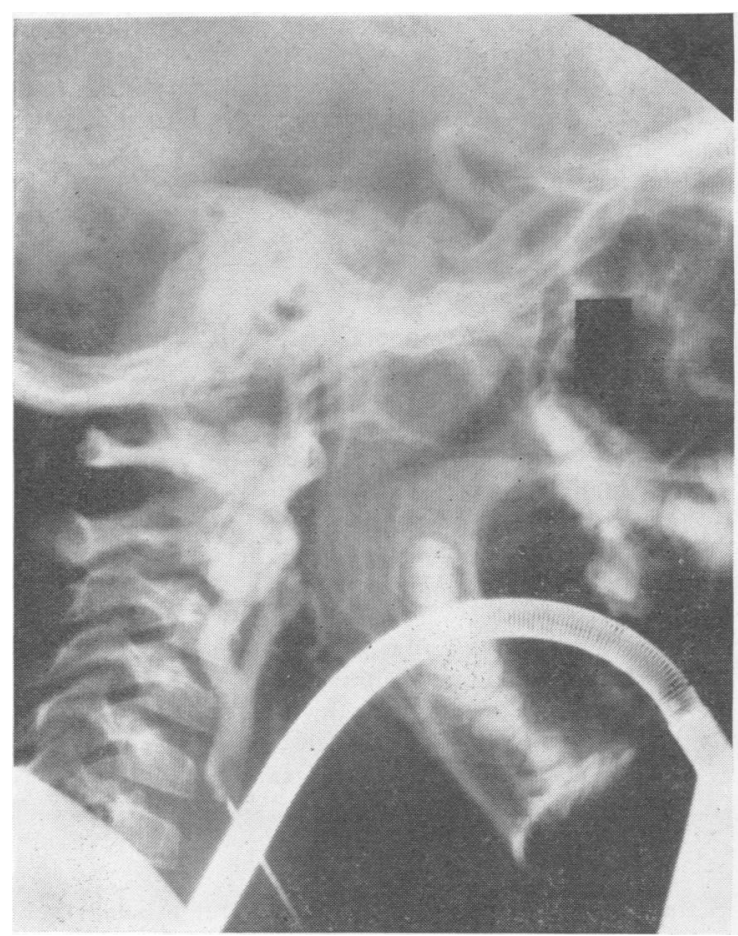

FIG. 1. Right carotid angiogram showing an internal carotid artery loop.

following history. She was born normally and had normal development until 14 months of age when she had generalized convulsions and developed weakness of the left side of the body which cleared up in the next four hours. After this she had several left-sided fits and became very much retarded. The left arm and leg were clumsy. She was treated with anti-convulsants. At the age of 7 she had several attacks of weakness of the left side lasting for an hour or so without any convulsions.

In February and March 1965 she had four attacks of weakness of the right side lasting for a few hours and in one attack she developed aphasia and hemianopia without convulsions or loss of consciousness. It was on this occasion that she was admitted for investigation. By the time of admission she had improved greatly.

On examination she was mentally slow. There was mild receptive and expressive dysphasia, no motor or sensory deficit but the right plantar reflex was extensor. Other systems were normal and the blood pressure 110/70 $\mathrm{mm} \mathrm{Hg}$.

INVESTIGATIONS Full blood count, ESR and CSF were normal. Electroencephalography showed bilateral spikes and slow waves which were much more diffuse on the left side. The radiographs of chest and skull were normal. Carotid angiograms showed bilateral carotid kinks $4 \cdot 5$ $\mathrm{cm}$ above the bifurcation. The kink was more acute on

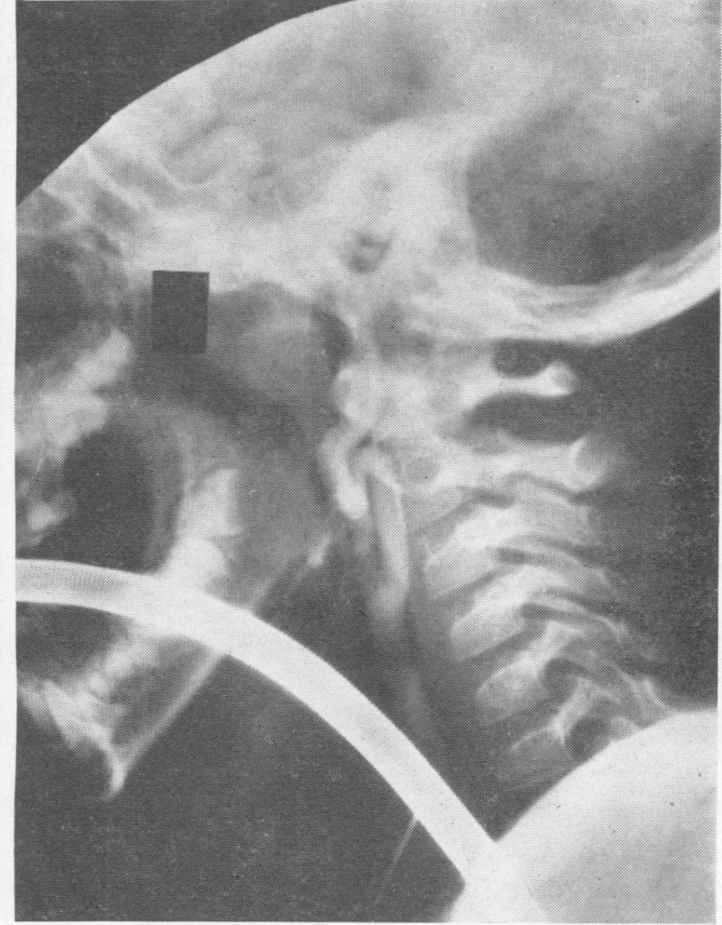

FIG. 2. Left carotid angiogram showing an internal carotid artery loop. Note: Angles between the limbs of the loops are more acute on the right side.

the right side (Fig. 3) than that on the left. The intracranial arteries on the left side and particularly the left middle cerebral group were of thinner calibre than those on the right. Pneumoencephalography (AEG) showed slight dilatation of both ventricles, left more than right, suggestive of atrophy.

FOLLOW-UP She is now $13 \frac{1}{2}$ years old and she has been attending a special school for handicapped children. There is still mild clumsiness of the left upper limb. The tendon reflexes are increased on both sides, left more than right and the right plantar response is still extensor.

\section{CASE 3}

A female child aged 3 years was admitted in January 1963 with the history that she was born normally and had normal development until the age of 18 months when she had a grand mal fit. Ever since she has continued to have focal fits affecting the right side, mainly the face and the hand with a frequency of one or two per day lasting for about three to five minutes. Her walking ceased and she developed weakness of the right side. After this her further development became retarded.

Examination showed a right hemiparesis with increased tendon reflexes on the right side and extensor right plantar reflex. There were no bruits and other systems were normal. 


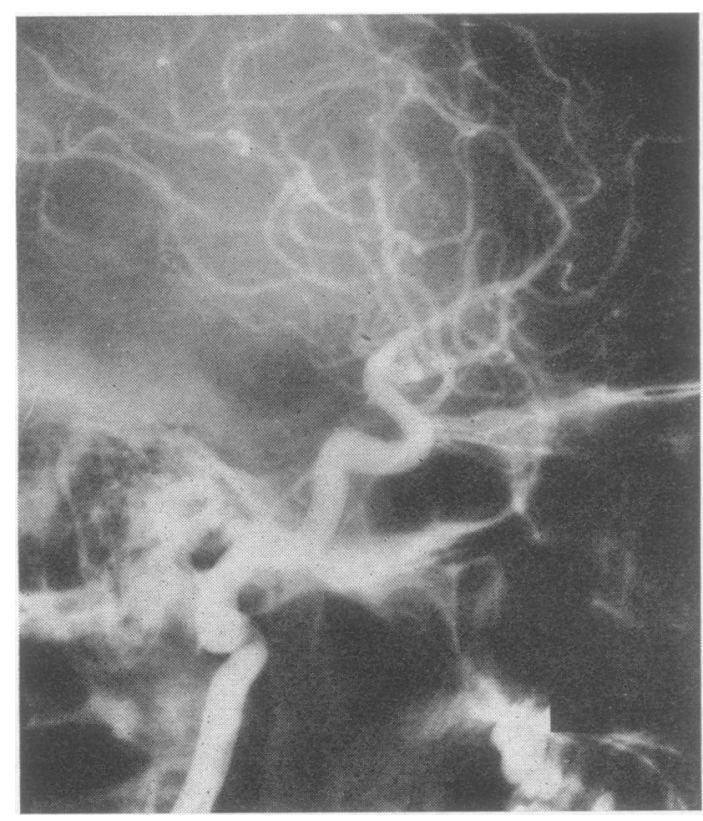

FIG. 3. Right carotid angiogram showing an acute kink of the internal carotid artery near the base of the skull.

INVESTIGATIONS Full blood count was normal and ESR $7 \mathrm{~mm}$ in one hour; serology was normal. The cerebrospinal fluid showed 2 cells and a protein of $27 \mathrm{mg}$ per $100 \mathrm{ml}$. Electroencephalography showed bilateral spikes and delta waves more diffuse on the left side. The radiographs of chest and skull were normal, but bilateral carotid angiograms showed marked looping of both internal carotid arteries (like Figs. 1 and 2) $2 \mathrm{~cm}$ above the bifurcation. The looping was more marked and more acute on the left side (like Fig. 1). Air encephalography showed distinct enlargement of the left ventricle with a shift to the same side suggestive of left cerebral atrophy.

FOLLOW-UP She is now 9 years old in a special school for handicapped children. She has twitchings of the right hand and right side of the face approximately once a month, in spite of anti-convulsants. Her speech and vocabulary are similar to a child of 4 years of age. She is left with a permanent right hemiparesis and marked mental retardation.

\section{CASE 4}

A male child aged 9 years who was born normally and had normal milestones was admitted in November 1968. He was well up to the age of 4 years when he developed jerking of the left side of the body just after waking in the morning. He had a similar attack five months before admission. These lasted for about two minutes. He had a further four episodes of twitching of the left side but they were associated with loss of consciousness lasting for about 10 minutes. Sometimes he felt that his left arm was heavy and he could 'feel another arm growing over his left arm.' This feeling frightened him.

Examination revealed a left-handed boy of normal intelligence with a small capillary naevus on the back. There was mild weakness of extension of the left wrist and left elbow with weakness of dorsiflexion of the left ${ }^{c}$ foot and flexion of the left hip. Tendon reflexes were $D$ equal and the left plantar response abnormal. Other systems were normal.

INVESTIGATIONS Full blood count, ESR, serology and CSF were normal. Electroencephalography showed slow $\vec{F}$

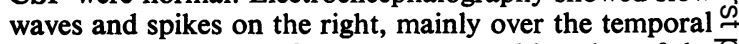
region. Radiography of chest was normal but that of the skull showed the right half to be larger than the left. 흔 Carotid angiograms showed a loop on the right side $\frac{\bar{\rho}}{\partial}$ $3.5 \mathrm{~cm}$ above the bifurcation of the common carotid. $\mathbb{\Phi}$ The limbs of the loop were shorter than that shown in Fig. 2. Pneumoencephalography was normal.

Follow-UP He was seen one year later and had had noattacks. He is attending a normal school and the attacks $\vec{\omega}$ are well controlled with anti-convulsants. Sometimes he? has headaches and periods of depression. The left-sided 5 weakness has improved. Repeat EEG showed similar? abnormality as above.

\section{CASE 5}

A male child aged 8 years was admitted in August 1985 with a one year history of giddiness, when his surround-은 ings seemed to rotate anti-clockwise and he had dey dreams. He stared, could not speak, and said he coudd see daggers, ships colliding and sometimes being smasheg. These lasted for a few seconds and occurred at a frequenty $\vec{a}$ of six to eight per week. In some attacks he uttered mestaingless words. He never had weakness of the limbs :or. generalized convulsions. He was right handed. Examination did not reveal any abnormal signs.

INVESTIGATIONS Full blood count, ESR, serology, ando CSF were normal. Electroencephalography showed slow waves with spikes mainly over the left temporoparietal region. The radiographs of chest and skull were norma $\vec{F}$ and carotid angiograms showed a loop of the left internal 3 carotid artery $4.3 \mathrm{~cm}$ above the bifurcation (like Fig. 2)? Both anterior cerebral arteries filled from the left sideo and were shifted to the left. Pneumoencephalography showed slight enlargement of the left lateral ventricle with displacement to the left suggesting a minor degree of cerebral atrophy.

FOLLOW-UP He is now 12 years of age and is quite wello studying at a normal school. $\mathrm{He}$ is on anti-convulsantş and occasionally has minor attacks but without halo lucinations. They last for a second or two. Electroencephalography repeated after four years showed shor runs of alpha activity on the left side but predominane delta activity and irregular spikes.

\section{CASE 6}

A female child aged $3 \frac{1}{2}$ years was born normally and had 
normal development until eight months before admission in July 1966 when she had a grand mal fit. She was unconscious for half an hour. This was followed by three or four attacks of generalized convulsions and after the second attack she developed weakness of the right arm and the right leg. There was some improvement in the leg but very little in the arm. She was right handed.

Examination revealed a girl of normal intelligence with right facial weakness and right hemiparesis. The right arm was affected much more than the right leg with spasticity. She walked with a hemiplegic gait. All other systems were normal.

INVESTIGATIONS Full blood count, ESR, CSF, and serology were normal. EEG showed quite normal alpha activity on the right side and delta activity was the predominant rhythm on the left side. The straight radiographs of chest and skull were normal but the carotid angiograms showed a kink of the left internal carotid artery $3.5 \mathrm{~cm}$ above the bifurcation. The pericallosal arteries filled from the right side. Pneumoencephalographs showed enlargement of the left lateral ventricle and a shift to the left suggestive of early cerebral atrophy.

Follow-up She is now $6 \frac{1}{2}$ years old and is at a special school for disabled children. In spite of routine anticonvulsants, she has fits once every 10 to 12 weeks which mainly affect the right side. These are followed by weakness and flaccidity of the right upper limb which improves in the next few hours. She is now left handed and has signs of mild right hemiparesis with spasticity.

\section{CASE 7}

A male patient aged 16 years was admitted in February 1963 with a history that three months before, while he was carrying a package on his right shoulder, he lost the vision in the right eye for about two minutes. After this he has had about six or seven such episodes mostly related to bending or turning the head. Sometimes they were followed by headache. There was no associated paraesthesia or weakness of the limbs or any speech disturbance. In the referral hospital a left temporal field defect was found.

Examination revealed a boy of normal intelligence. Fundi and visual fields were normal and there were no other neurological signs. Blood pressure $128 / 80 \mathrm{~mm} \mathrm{Hg}$, and other systems were normal. There was a distinct murmur over the right carotid artery and a faint one over the left.

INVESTIGATIONS Full blood count, ESR, serology, and CSF were normal. Electroencephalography showed bilateral slow activity. At times there were delta waves coming from the right parietal region. The radiographs of chest and skull were normal. Carotid angiograms showed bilateral internal carotid loops $4.3 \mathrm{~cm}$ above the bifurcation. The limbs of the loop were like those of case 2 (like Fig. 2) but they were longer on the right side.

At the time of lumbar puncture the neck was flexed and he developed loss of vision of the right eye. The arteries of the right fundus were very much narrowed. He was given inhalations of carbon dioxide for four to five minutes and his vision improved.

He also had two attacks of paraesthesia and rigidity of the left side while the investigations were being completed.

FOLLOW-UP During the six years after discharge he has had two further attacks of loss of vision in the right eye and an attack of transient weakness of the left side, related to neck rotation. He was not sure of the side but possibly it was on the right. He has not had any attacks for the last two years.

\section{CASE 8}

A male aged 9 $\frac{1}{2}$ months was admitted in May 1961 with a history that about three weeks before in the morning he did not look well and was rather drowsy and in the evening developed generalized convulsions. After this he had several right-sided convulsions and he developed weakness of the right side and failed to recognize his parents. The weakness gradually improved but he was not using his right hand properly and movement on the right was diminished compared with the left. He was right handed.

Examination showed him to be conscious with normal fundi and visual fields. He was not moving the right limbs as well as the left and the tendon reflexes on the right were brisker with a right extensor plantar reflex. There was no throat or chest infection and other systems were normal.

INVESTIGATIONS Blood count showed a haemoglobin of $10.2 \mathrm{~g} / 100 \mathrm{ml}$. and CSF was normal. Complement fixation tests for viruses were negative. Electroencephalography showed left-sided slow waves and generalized less formed alpha activity as compared with the right. The radiographs of chest and skull were normal and carotid angiograms revealed a loop of the left internal carotid artery forming a circle $2.5 \mathrm{~cm}$ above the bifurcation (Fig. 4).

Follow-UP $\mathrm{He}$ is now $8 \frac{1}{2}$ years old and in a normal school. His intelligence is a little below average and he is left handed. He still has slight clumsiness of the right hand and has minor temporal lobe attacks at a frequency of one a week on average. Sometimes he has twitching of the right side, mainly the face and the hand. Twice he was admitted with continuous twitching of the right side of the body and once he went into status epilepticus, but the fits were quickly controlled by anti-convulsants which he is still taking.

\section{CASE 9}

A male child aged 20 months was well until three weeks before admission in June 1969 when he went off his food and vomited two or three times. He would not walk. After four days his appetite came back but he still could not walk. About a week later his parents noticed that he could not use his right arm. There were no fits and no history of infection. He was talking as usual. He was born normally and until the age of 20 months development had been normal. 


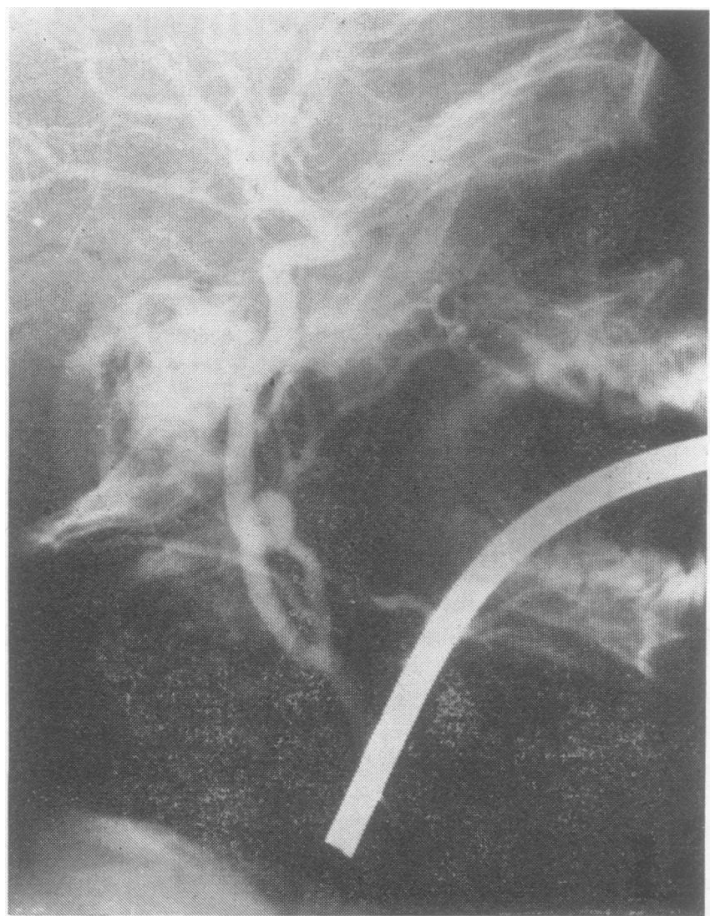

FIG. 4. Left carotid angiogram showing a circular loop of internal carotid artery.

Examination revealed a child of normal intelligence. There was right facial weakness of upper motor neurone type and moderate right hemiparesis; the arm was affected more than the right leg. The tendon reflexes were exaggerated on the right side and the right plantar response was extensor. All other systems were normal.

INVESTIGATIONS Full blood count, ESR, serology, and CSF were normal. Agglutination tests for viruses were negative. Electroencephalography showed some reduction of the alpha waves on the left with irregular theta activity. Response to photic stimulation was reduced on the left side.

Carotid angiograms showed bilateral carotid loops $3.2 \mathrm{~cm}$ above the bifurcation. The loop was far more exaggerated on the left than the right (Figs. 5 and 6). The slight narrowing on the right was thought to be due to angiographic technique because the needle was dislodged during radiological manoeuvres.

FOLLOW-UP He was seen six weeks after discharge when he still had some weakness on the right side and the right-sided tendon reflexes were brisker than those on the left with extensor right plantar response.

\section{DISCUSSION}

The clinical picture of these cases is fairly uniform.
The features consist of generalized epileptic attacks (six cases), hemipareses (seven cases), attacks of loss of vision and hemianopia in two cases, and dysphasia in one. Angiography, which was carried out because of this symptomatology, demonstrated loops and kinks on the relevant side. If there were bilateralloops and kinks the patient showed alternating hemiparesis (cases 1 and 2) or the affected side had more pronounced looping or associated kink-that is, more acute angles between the two segments of the loop. The relevant side showed more marked EEG changes and evidence of cerebral atrophy on air encephalography. This clinical picture suggests another cause of infantile hemiplegia and the presentation is similar to the cases reported by Bickerstaff (1964) where the extracranial portion of the internal carotid arteries showed irregularities and even occlusion related to infection of surrounding structures. In the cases reported here, no evidence of infection was found and there was no evidence of any other causes for infantile hemiplegia. Neithe was there any cardiac lesion, vascular malformation nor any changes in the CSF suggestive of infection

The impression that the loops and kinks are responsible for the neurological syndromes is further strengthened by the follow-up studies which have shown that four patients are left with permanent $\vec{\theta}$ neurological deficits. They are mentally backwar $\overline{\mathbb{P}}$ and in special institutions for handicapped children: Two suffer from focal epileptic attacks and their EEG records contain obvious abnormality on the appropriate side to the loops. Only one patient is quite well and has not had any further symptoms for two years (case 7). Patient no. 3 is virtually symptom free from the neurological point of view. Patient no. 9 is the most recent case and the followup has not been long enough to draw any final conclusions. On careful analysis of the radiological features and characteristics of the loops it is evident that those who are more disabled than others do show more pronounced angulations in the limbs of the loops on the appropriate sides.

The origin of the loops in these cases is undoubtedly congenital and developmental. Cairney (1924) demonstrated these abnormalities in the dissection of the neck of foetuses ranging from five months' gestation to full term. Five of them had bilateral loops. This is related to embryological development when incomplete straightening of the junction of the third branchial arch and dorsal aorta occurs as these join to form the internal carotid artery. The straightening occurs during foetal development when the foetal heart and large vessels recede in the thoracic cavity. As the embryonic bend persists in different degrees it produces different kinds of undulations, loops, and kinks. 


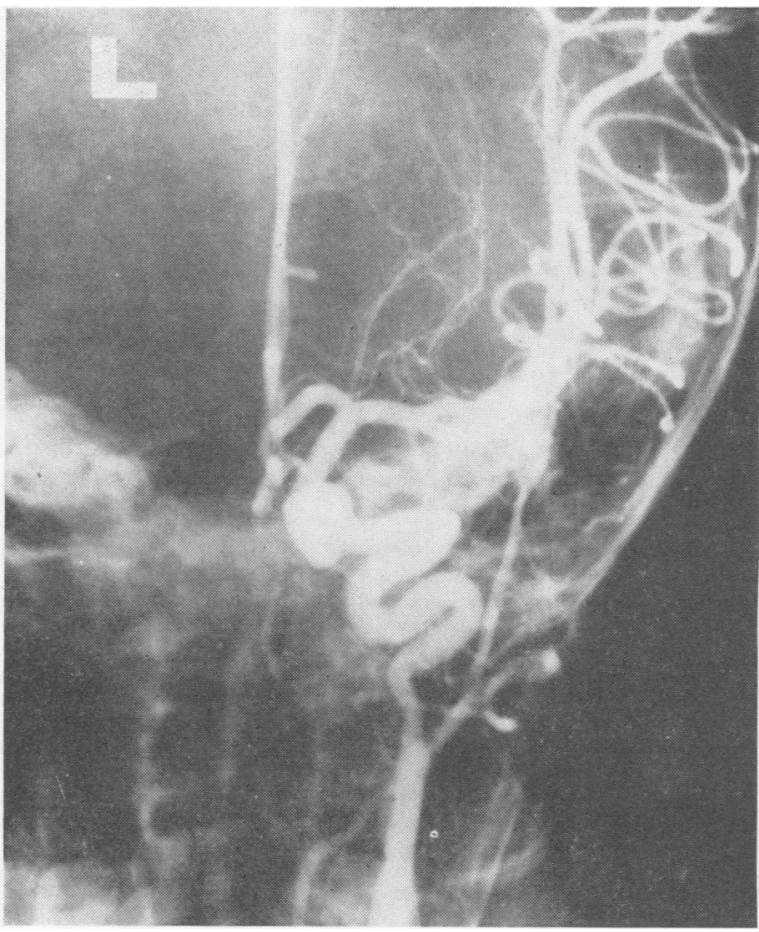

FIG. 5 .

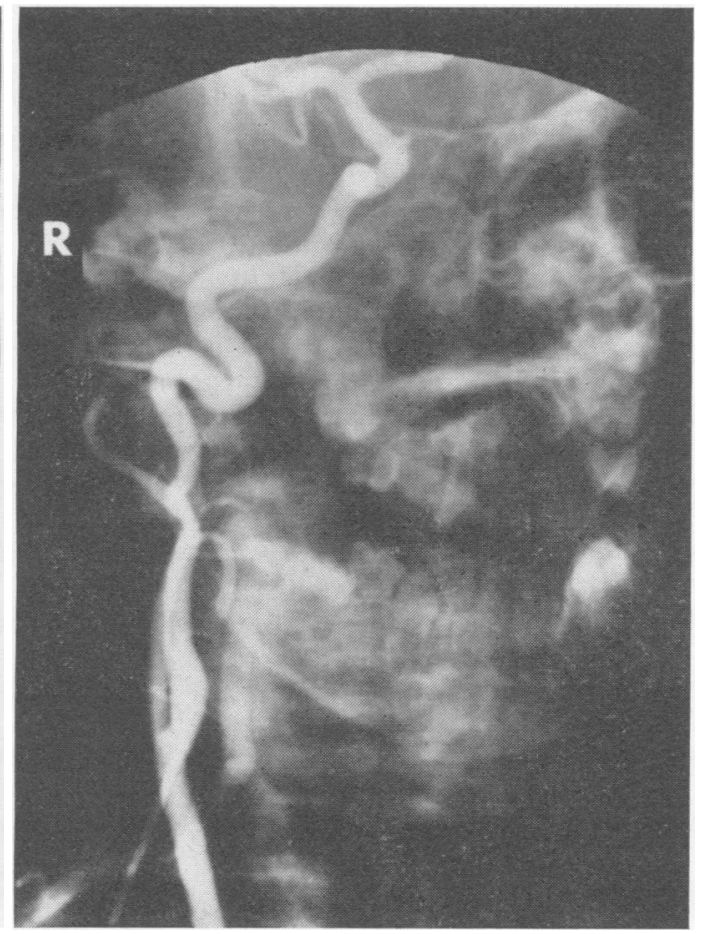

FIG. 6.

Left and right carotid angiograms showing bilateral hops but much more exaggerated on the left side.

It is evident from this study that the clinical syndrome is ischaemic in nature, but it is difficult to explain how such loops might be responsible for the vascular insufficiency. So far there is no satisfactory explanation which can be put forward. It is very tempting to suggest that during rotation of the neck the angulation could be exaggerated and produce obstruction to the blood flow. This has been seen to happen during angiography. Bauer, Sheehan, and Meyer (1961) found that kinking of the tortuous internal carotid occurred when the neck was rotated during angiography. Toole and Tucker (1960) demonstrated the same phenomenon in cadavers when perfusion was made at a constant pressure in the aorta. But, if the collateral circulation is adequate, which it usually is in children, why should the ischaemic symptoms develop? This may be explained on the following theories.

1. The obstruction is possibly so sudden that collateral circulation does not have time to be effective. As a child's brain is very susceptible to the slightest insult, ischaemia for a very short time might be enough to cause fits and hemiparesis.

2. During rotation of the neck the kink may be exaggerated and cause obstruction to blood flow and thus produce distension of the proximal portion of the internal carotid artery. This could stretch the carotid sinus and trigger the carotid sinus mechanism producing a fall of blood pressure, so that development of adequate collateral circulation might be hampered. It is also possible that this distension might stimulate the sympathetic system producing narrowing of the distal branches.

3. During rotation of head and neck, when the circulation is obstructed, it is possible that soft fibrin and platelet thrombi may be formed at the kinks. These could act as microemboli producing the features of infantile hemiplegia.

As the tortuosity and kinking are congenital in origin, there might be an associated fibrous band or cord crossing the internal carotid artery at the particular point which might occlude the vessel during neck movement. This has been seen in a necropsy by one of us (J. MacD. H.) in an adult patient.

The patients discussed in this paper were not given any specific treatment apart from physiotherapy, proper rehabilitation, and anti-convulsants. As the exact mechanism of production of ischaemia was not clear and as our attention has only recently bee 
attracted towards the internal carotid artery loops no attempt at correction of loops was undertaken. In adults with this condition some surgical methods of treatment have been used by others. Riser and his colleagues (1951) reported a case where the redundant coil was straightened and the artery was suspended to the underside of the sterno-mastoid which cured the symptoms of internal carotid insufficiency. Another method used was resection of the loop and end-to-end anastomosis (Smathers and Smathers, 1959). Quattlebaum, Upson, and Neville (1959) reported three cases in two of which the common carotid was joined to the internal carotid artery after resection of the bifurcation with sacrifice of the external carotid arteries. In their third case a portion of common carotid artery was resected in order to reduce the kinking of the internal carotid artery.

We suggest that further work is needed to evaluate the clinical significance of carotid artery loops in children and their surgical treatment. The main aim of this paper is to emphasize that carotid loops should be kept in mind as a cause of infantile hemiplegia because surgical treatment might be possible. Early detection of such cases and correction of loops might prevent disability and mental retardation in an otherwise normal child.

\section{SUMMARY}

Eight cases below 10 years of age and one 16 years of age, have been reported who presented with features of cerebrovascular insufficiency. These were considered related to internal carotid artery loops on the basis of clinical picture, EEG abnormality, and presence of a loop in the cervical portion of the internal carotid artery on the relevant side on angiography. Air encephalography showed some cerebral atrophy on the appropriate side. It appears that the severity of symptoms is related to the degree of angulation between the limbs of the loop. Four of these cases who are permanently disabled have severe angulation of the loops. Two patients suffer from focal fits and have EEG abnormalities on the side of the loops. The mechanism of production of ischaemia has been discussed and some theories put forward. It is suggested, from experience of the above cases, that internal carotid artery loops and kinks should be borne in mind as the cause of infantile hemiplegia.

We thank Mr. J. M. Small and Mr. J. G. Hamilton for permission to include their cases and Dr. C. P. Moxon for permission to study the angiograms. We greatly appreciate the help of Miss Susan Ray at various stages.

\section{REFERENCES}

Bauer, R., Sheehan, S., and Meyer, J. S. (1961). Arteriographic study of cerebrovascular disease. Arch. Neurol. (Chic.), 4, 119-131.

Bickerstaff, E. R. (1964). Aetiology of acute hemiplegia in childhood. Brit. med. J., 2, 82-87.

Cairney, J. (1924). Tortuosity of the cervical segment of the internal carotid artery. J. Anat., 59, 87-96.

Connolly, J. H. (1914). Large pulsating vessels in the right portion of the posterior pharyngeal wall, partly concealed behind the right tonsil in a boy of five. Proc. roy. Soc. Med., 7, 25-26.

Coulson, W. (1852). Peculiar disposition of the large vessels, producing a tremor at the root of the neck. Trans. path. Soc. Lond., 3, 302.

Fisher, A. G. T. (1915). Sigmoid tortuosity of the internal carotid artery and its relation to tonsil and pharynx. Lancet, 2, 128-130.

Garaseferian, R. O. (1965). Patholoogicheskaia Izitost Sonnoe arterii ice Zuachenic v Narushenii Mozgovogo krovoobrashcheniia. Zh. Nevropat. Psikhlat. Korsakov, 65, 119-131.

Jackson, J. L. (1933). Tortuosity of internal carotid artery and it relation to tonsillectomy. Canad. med. Ass. J., 29, 475-479.

McDowell, F. H., Schick, R. W., Frederick, W., and Dunbar, H. S§ (1959). An angiographic study of cerebrovascular disease Arch. Neurol. (Chic.)., 1, 435-442.

Metz, H., Murray-Leslie, R. M., Bannister, R. G., Bull, J. W. D. and Marshall, J. (1961). Kinking of the internal carotid arter in relation to cerebrovascular disease, Lancet, 1, 424-426.

Quattlebaum, J. K., Jr., Upson, E. T., and Neville, R. L. (1959) Stroke associated with elongation and kinking of internat carotid artery: Report of three cases treated by segmenta? resection of the carotid artery. Ann. Surg., 150, 824-832.

Riser, M. M., Géraud, J., Ducoudray, J., and Ribaut, L. (1951). Dolicho-carotide interne avec syndrome vertigineux. Rev. Neurol., 85, 145-147.

Smathers, H. M., and Smathers, W. M. (1959). Carotid artery occlusion. Arch. Surg., 79, 276-284.

Toole, J. F., and Tucker, S. H. (1960). Influence of head position upon cerebral circulation studies on blood flow on cadavers. Arch. Neurol. (Chic.)., 2, 616-623.

Weibel, J., and Fields, W. S. (1965). Tortuosity, coiling and kinking of the internal carotid artery, I. Etiology and radiographic anatomy. Neurology (Minneap.), 15, 7-18.

-, (1965). Tortuosity, coiling and kinking of the internal carotid artery, II. Relationship of morphological variation to cerebrovascular insufficiency. Neurology (Minneap.), 15, 462-468. 